\title{
Biodegradable poly(D,L-lactide-co-glycolide)/poly(L- $\gamma$-glutamic acid) nanoparticles conjugated to folic acid for targeted delivery of doxorubicin
}

\author{
Laura Jaimes-Aguirre a , Enrique Morales-Avila a,*, Blanca E. Ocampo-García ${ }^{\mathrm{b}}$, Luis Alberto Medina ${ }^{\mathrm{c}, \mathrm{d}}$, \\ Gustavo López-Téllez ${ }^{\mathrm{e}}$, Brenda V. Gibbens-Bandala ${ }^{\mathrm{a}}$, Vanessa Izquierdo-Sánchez ${ }^{\mathrm{c}}$ \\ a Universidad Autónoma del Estado de México, Facultad de Química Toluca, Mexico \\ b Instituto Nacional de Investigaciones Nucleares, Departamento de Materiales Reactivos Ocoyoacac, Mexico \\ ' Instituto de Física, Universidad Nacional Autónoma de México, Ciudad de México 04510, México \\ d Mexico Unidad de Investigación Biomédica en Cáncer INCan/UNAM, Instituto Nacional de Cancerología, Ciudad de México 14080, México \\ e Universidad Autónoma del Estado de Mexico, Centro Conjunto de Investigación en Química Sustentable UAEM/UNAM, Mexico
}

\section{A R T I C L E I N F O}

\section{Article history:}

Received 13 September 2016

Received in revised form 8 March 2017

Accepted 13 March 2017

Available online 18 March 2017

\section{Keywords:}

Folic acid

PLGA nanoparticles

Targeted drug delivery

Multimeric FA nanoparticles

Sustained-release system

\begin{abstract}
A B S T R A C T
A novel targeted drug delivery nanoparticle system based on poly(D,L-lactide-co-glycolide) acid (PLGA) for delivery of doxorubicin (DOX) was developed. DOX-PLGA NPs were obtained by the emulsification-solvent evaporation technique. Then, their surface was modified with poly( $\mathrm{L}-\gamma$-glutamic acid) ( $\gamma$-PGA) and finally conjugated to modified folic acid (FA) as a targeting ligand. The surface modification and FA conjugation were followed by UV-Vis and FT-IR spectroscopies. Morphology was observed by TEM/SEM. Particle size, PDI and zeta potential were measured using DLS studies. Encapsulation and loading efficiencies, and DOX release kinetics were determined. Specific uptake and cell viability of DOX-PLGA/ $\gamma$-PGA-FA NPs were tested in HeLa cells. Quasi-spherical nanoparticles with a particle size lower than $600 \mathrm{~nm}$ (DLS) were obtained. Spectroscopic techniques demonstrated the successful surface modification with $\gamma$-PGA and FA conjugation. Release profile of DOX-PLGA $\gamma$-PGA-FA NPs showed a release of $55.4 \pm 0.6 \%$ after seven days, in an acidic environment. HeLa cells exhibited a decrease in viability when treated with DOX-PLGA/ $\gamma$-PGA-AF NPs, and cellular uptake was attributed to FA receptor-mediated endocytosis. These results suggest that DOX-PLGA/ $\gamma$-PGA-FA NPs are a potential targeted drug carrier for further applications in cancer therapy.
\end{abstract}

(c) 2017 Elsevier B.V. All rights reserved.

\section{Introduction}

Nanotechnology is the science that deals with processes and phenomena that occur at molecular level and nanoscale range [1]. In the last century, the nanotechnology has had a profound impact and potential benefits on our society, with applications in nanoelectronics, energy production, consumer products, biomaterials and nanomedicine.

Nanomedicine comprises the process of diagnosing, treating, curing, and preventing diseases by using nanomaterials. These processes also include those used outside the patient, in-line biosensors and surgical tools, and advanced biomaterials designed for tissue engineering and to promote tissue repair [2-4]. Among the nanomaterials used in the treatment of several diseases, an important fraction corresponds to

\footnotetext{
* Corresponding author at: Facultad de Química, Universidad Autónoma del Estado de México, Paseo Tollocan esq Paseo Colón S/N, Toluca, Estado de México, C.P. 50120, Mexico. E-mail addresses: enrimorafm@yahoo.com.mx, emoralesav@uaemex.mx (E. Morales-Avila)
}

polymers that form nanoparticles (solid colloidal particles ranging from 1 to $1000 \mathrm{~nm}$ in size) [5], in which excipients may alter release time and increase efficacy of active ingredients, being encapsulated in the polymeric matrix or directly conjugated to the polymer $[6,7]$.

These novel drug delivery systems are frequently more effective than their freely-delivered counterparts. In cancer therapy, the advantages of the polymeric nanoparticles include (a) delivery systems that can extend drug circulation half-life, (b) increased drug concentration at the tumour site through the passive Enhanced Permeation and Retention (EPR) effect, and (c) reduced non-specific uptake due to active targeting [8].

One of the most widely used polymers in the fabrication of polymeric nanoparticles is the copolymer poly(D,L-lactide-co-glycolide) acid (PLGA), due to its biocompatible and biodegradable properties $[7,8]$. Furthermore, PLGA exhibits many of the ideal properties of a nanoscale delivery system, allowing the encapsulation of the drug within the polymer matrix and providing long-term release of the encapsulated agent $[9,10]$. 
PLGA-based systems have been used in the treatment of cancer, showing a notable improvement of the therapy [11-15]. Drug release can be modulated by manipulating several parameters related to PLGA degradation, such as pH. PLGA can be degraded into shorter chain alcohols and acids upon exposure to the acidic microenvironment (approximately $\mathrm{pH}$ 5.3) around tumour tissues. Accordingly, drugs can be distributed around tumour microenvironment [16].

On the other hand, PLGA lacks reactive main or side chains, making the interaction with biological systems and the modification with biologically-active moieties difficult, restricting its application. Poly(L- $\gamma$ glutamic acid) ( $\gamma$-PGA) is an anionic homopolyamide widely used in nanoparticulate systems because of its hydrophilicity and the improvement in the interaction between polymers (e.g. PLGA) and biological systems [17-23].

Despite the fact that most nanoparticles are expected to accumulate in tumours due to the EPR effect, passive approaches suffer from several limitations. A useful strategy to achieve efficient tumour targeting and to overcome these limitations is to conjugate carriers with specific ligands that recognize and bind to their cognate receptors on the surface of cancer cells through ligand-receptor interactions that induce receptor-mediated endocytosis and drug release inside the cell [24]. Efficient binding and internalization requires that receptors are over-expressed homogenously on target cancer cells with respect to those on normal cells. The cell receptors density and ligands, three-dimensional architecture of nanoparticles, ligand conjugation chemistry and the types of ligands available may affect ligand-receptor interactions, which may be enhanced by the multivalent nature of the nanoparticle (NP), achieving a high targeting specificity and delivery efficiency, while avoiding nonspecific binding and possible cell resistance mechanisms [25,26].

One of the most widely studied small molecules as a targeting moiety for the delivery of agents is folic acid (FA). FA receptors are selectively over-expressed in a number of tumour cell types, but present in low or non-detectable levels in most normal cells [24]. Besides, FA has a high binding affinity for the folate receptor $\left(\mathrm{Kd}=10^{-9} \mathrm{M}\right)$, and is internalised via receptor-mediated endocytosis, making it a good targeting candidate for nanocarriers delivering an active agent into the cells $[24,26]$.

The aim of this work was to develop a novel PLGA $/ \gamma$-PGA-based drug delivery system conjugated with folic acid for delivery of the anticancer model drug DOX and targeted against folate receptors over-expressed in some types of cancer cells.

\section{Materials and methods}

\subsection{Materials}

Poly(D,L-lactide-co-glycolide) acid terminated had a lactide to glycolide ratio of 75:25. Polymer molecular weight was 11,300 g/mol. Poly(vinyl alcohol) (Mowiol®4-88), with a 31,000 g/mol molecular weight, had $88.0 \%$ mol hydrolysis and $10.5 \%$ residual content of acetyl. Poly-L- $\gamma$-glutamic acid sodium salt had a molecular weight $\geq 750 \mathrm{kDa}$ (MALLS). Folic acid (HPLC purity $\geq 97 \%$ ). N-(3-Dimethylaminopropyl)$\mathrm{N}^{\prime}$-ethylcarbodiimide hydrochloride (EDC), doxorubicin hydrochloride 98.0-102.0\% (HPLC). RPMI-1640 medium, N-Hydroxysulfosuccinimide sodium salt (NHSS) $\geq 98 \%$ (HPLC). These chemicals were all purchased from Sigma-Aldrich (St. Louis, MO, USA) and used without purification. Other chemicals and solvents were of reagent grade. The HeLa cell line was obtained from National Institute of Cancerology, Mexico.

\subsection{Methods}

\subsubsection{Preparation of PLGA nanoparticles}

PLGA nanoparticles were prepared using the single emulsificationsolvent evaporation method and PVA [poly(vinyl alcohol)] as stabilizer [10]. A preliminary study was performed based on a multifactorial twotier design. PLGA in acetone solutions $(10 \mathrm{mg} / \mathrm{mL}$ and $15 \mathrm{mg} / \mathrm{mL})$ and aqueous PVA solutions $(0.25,0.5,1,3,10[\% w / v])$, were evaluated. The best combination in terms of the smallest particle size and the highest encapsulation and/or DOX-loading efficiency was chosen to prepare PLGA nanoparticles. Briefly, $0.66 \mathrm{~mL}$ of methanol was mixed with $0.5 \mathrm{~mL}$ of PLGA acetone solution and vortexed. Immediately after, the solution was slowly dropped over $3.64 \mathrm{~mL}$ of aqueous PVA solution and ultra-sonicated for $10 \mathrm{~min}$. Afterwards, acetone and methanol were evaporated by rotary vacuum evaporation $\left(65^{\circ} \mathrm{C}, 40 \mathrm{rpm}, 15 \mathrm{~min}\right)$. Finally, the aqueous solution was centrifuged for $20 \mathrm{~min}$ at $4400 \mathrm{rpm}$. The supernatant was collected, freeze-dried and stored for further use.

\subsubsection{DOX loading and encapsulation efficiency}

Once PLGA and PVA concentrations were established, various DOX concentrations (13.6, 21.7, 32.4, 42.9, 53.4, 104, $241.2[\mu \mathrm{g} / \mathrm{mL}]$ ) were evaluated in order to find the saturation point of the nanoparticle system.

The DOX-PLGA nanoparticles were prepared by adding different volumes of $2 \mathrm{mg} / \mathrm{mL}$ DOX solution to a solution of PLGA in acetone. The solution was stirred for $25 \mathrm{~min}$. After centrifugation, the supernatant was ultra-centrifuged at $22000 \mathrm{x}$ g for $10 \mathrm{~min}$. The supernatant was collected, and the pellet was washed and re-suspended in injectable-grade water (Fig. 1a). The DOX-loaded amount was determined by UV-Vis spectroscopy. Absorbance of supernatants was measured at $480 \mathrm{~nm}$, according to DOX absorbance. Encapsulation efficiency (\%EE) and loading efficiency (\%LE) percentages were calculated as follows:

$$
\begin{aligned}
& \% \mathrm{EE}=\frac{D O X_{\text {added }}-D O X_{\text {non encapsulated }}}{D O X_{\text {added }}} \times 100 \\
& \% \mathrm{LE}=\frac{D O X_{\text {added }}-D O X_{\text {non encapsulated }}}{P L G A_{\text {added }}} \times 100
\end{aligned}
$$

\subsubsection{Modification of DOX-PLGA nanoparticles with $\gamma$-PGA}

DOX-PLGA/ $\gamma$-PGA nanoparticles were obtained by the Kuo and $\mathrm{Yu}$ method [19]. Briefly, $10 \mathrm{mg}$ of lyophilised DOX-PLGA nanoparticles, $96 \mathrm{mg}$ ( $0.50 \mathrm{mmol})$ of EDC and $23 \mathrm{mg}(0.19 \mathrm{mmol})$ of NHSS were dissolved in $15 \mathrm{~mL}$ of injectable-grade water by stirring for $4 \mathrm{~h}$. After that, $5 \mathrm{mg}$ of $\gamma$-PGA was added and stirred for $4 \mathrm{~h}$ at room temperature. The resulting solution was purified by ultracentrifugation in centrifugal filters (Amicon® Ultra $30 \mathrm{kDa}$ ). DOX-PLGA $/ \gamma$-PGA nanoparticles were washed and re-suspended in $10 \mathrm{~mL}$ of injectable-grade water (Fig. 1b).

\subsubsection{Functionalization of DOX-PLGA/ $\gamma$-PGA nanoparticles with folic acid}

$11 \mathrm{mg}$ of folic acid (FA, $24.42 \mu \mathrm{mol}), 9.2 \mathrm{mg}(79.94 \mu \mathrm{mol})$ of NHSS and $72 \mathrm{mg}$ ( $0.37 \mathrm{mmol})$ of EDC were dissolved in $10 \mathrm{~mL}$ of injectablegrade water. The mixture was stirred for $4 \mathrm{~h}$. After that, $1 \mathrm{~mL}$ of $1.5 \mathrm{mg} / \mathrm{mL}$ ethylenediamine (EDA, $24.95 \mathrm{mM}$ ) solution was added to the FA solution and stirred for $4 \mathrm{~h}$ (Fig. 1c).

Meanwhile, $48 \mathrm{mg}(0.25 \mathrm{mmol})$ of EDC and $15 \mathrm{mg}$ of NHSS were added to $10 \mathrm{~mL}$ of DOX-PLGA/ $\gamma$-PGA solution and stirred for $4 \mathrm{~h}$. Afterwards, FA solution was added to the DOX-PLGA $/ \gamma$-PGA solution and stirred for $4 \mathrm{~h}$, in order to obtain DOX-PLGA $/ \gamma$-PGA-FA conjugated nanoparticles. The mixture was purified through centrifugal filters. DOX-PLGA $/ \gamma$-PGA-FA nanoparticles were washed and suspended in $5 \mathrm{~mL}$ of injectable-grade water. Finally, DOX-PLGA/ $\gamma$-PGA-FA nanoparticles were freeze-dried and stored for posterior use (Fig. 1d).

\subsubsection{DOX-PLGA/ $\gamma-P G A-F A$ nanoparticle stability assay}

Freeze-dried nanoparticle samples were stored for sixty days at room temperature. Posteriorly samples were rehydrated with injectable water, and size determination was performed. Rehydrated suspension was stored and particle size was measured after fifteen days. Particle size determinations were compared to measurement made prior freeze-drying process. 


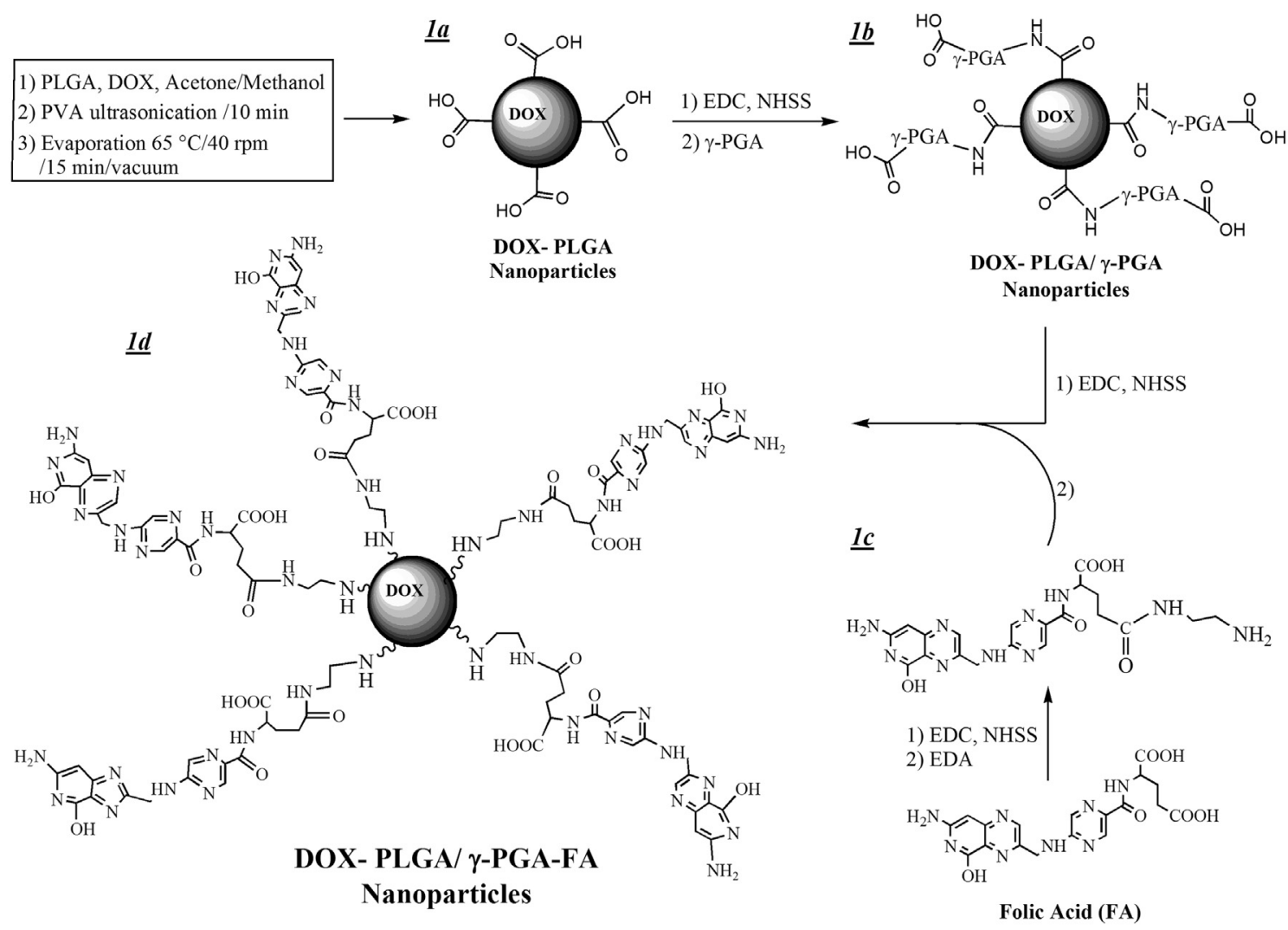

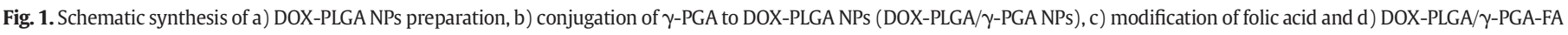
NPs.

\subsection{Characterization}

\subsubsection{Nanoparticle size and zeta potential}

Particle size (Dynamic light scattering, DLS) and zeta potential were measured using a Nanotrac analyzer (Nanotrac Wave, Model MN401, Microtract, FL, USA). Lyophilised samples were analysed using injectable-grade water as diluent. All measurements were performed with a wavelength of $657 \mathrm{~nm}$ at $20^{\circ} \mathrm{C}$, current of $15.79 \mathrm{~mA}$, electric field of $14.35 \mathrm{~V} / \mathrm{cm}$ and sampling time of $128 \mu \mathrm{s}$.

\subsubsection{UV-Vis spectroscopy}

Absorption spectra in the $190-800 \mathrm{~nm}$ range was obtained with a Thermo Genesys $10 \mathrm{~S}$ spectrometer using a 1-cm quartz cuvette. Nanoparticles were measured through UV-Vis analysis to monitor the conjugation reactions.

\subsubsection{FT-IR spectroscopy}

The IR spectra of lyophilised samples were acquired through a PerkinElmer System 2000 spectrometer with an ATR platform (Pike Technologies), by applying attenuated total reflection Fourier transform infrared (ATR-FT-IR) spectroscopy. Resolution $0.4 \mathrm{~cm}^{-1}, 40$ scans, and a $4000-400 \mathrm{~cm}^{-1}$ operating range.

\subsubsection{Transmission electron microscopy (TEM)}

The morphology of the nanoparticles was analysed through a Jeol JEM 2010 HT microscope operating at $200 \mathrm{kV}$. Samples were prepared for analysis by evaporating a drop of nanoparticle suspension on a carbon-coated TEM copper grid.

\subsubsection{Scanning electron microscopy (SEM)}

Surface topography was evaluated with a JEOL JSM 6510LV microscope operating at $20 \mathrm{kV}$, using secondary electron signals. Samples were sputtered with a thin layer of approximately $15 \mathrm{~nm}$ of gold using a Denton Vacuum DESK IV system.

\subsubsection{In vitro drug release kinetics}

Released DOX concentration was determined by UV-Vis spectroscopy after dialysis. Briefly, $30 \mathrm{mg}$ of either DOX-PLGA-NP or DOX-PLGA/ $\gamma$ PGA-FA nanoparticles were dispersed in $2 \mathrm{~mL}$ of phosphate buffered saline (PBS) and placed in a dialysis bag (30,000 Da MWCO). Then, the closed bag was immersed in a $50 \mathrm{~mL}$ tube containing $15 \mathrm{~mL}$ of PBS as the release medium at two different $\mathrm{pH}$ values $(\mathrm{pH} 7.4, \mathrm{pH}$ 5.3). The tube was then agitated $(110 \mathrm{rpm})$ at room temperature. At different time points ( 1 h, 3 h, 6 h, 8 h, 20 h, 1 day, 2 days, 3 days, and 7 days), $0.5 \mathrm{~mL}$ aliquots were removed for analysis and volume was replaced with fresh PBS.

\subsubsection{Cell culture}

Human cervix adenocarcinoma cells (HeLa) were cultured in sterile folate-free RPMI medium (Sigma-Aldrich, USA) supplemented with bovine faetal serum, penicillin $(100 \mathrm{UI} / \mathrm{mL})$, streptomycin $(100 \mu \mathrm{g} / \mathrm{mL})$, and amphotericin $(0.25 \mu \mathrm{g} / \mathrm{mL})$. The cells were incubated at $37{ }^{\circ} \mathrm{C}$ in a humidified environment and $5 \% \mathrm{CO}_{2}$.

\subsubsection{In vitro cellular uptake study}

Nanoparticle uptake by HeLa cells was evaluated. Cells were cultured in a 4 -well plate $\left(1 \times 10^{4}\right.$ cells per well). After $24 \mathrm{~h}$, medium was removed. To test whether nanoparticle uptake occurs via folate receptors, a group of HeLa cells were pre-treated with $500 \mu \mathrm{L}$ of free folic acid $(11 \mathrm{mg} / \mathrm{mL})$ in order to saturate receptors, and incubated at $37{ }^{\circ} \mathrm{C}$ for $2 \mathrm{~h}$. After receptor saturation, both blocked and non-blocked HeLa cells were treated with PLGA/ $\gamma$-PGA-FA nanoparticles $(675 \mu \mathrm{g} / \mathrm{mL})$ eluted in PBS for $3 \mathrm{~h}$. Finally, supernatants were collected and measured by UV-Vis spectroscopy at $280 \mathrm{~nm}$, wavelength corresponding to FA. Uptake percentage was calculated with regards to PLGA/ $\gamma$-PGA-FA 
nanoparticles in PBS that were not exposed to cells. The baseline was registered as untreated cells in the same conditions. The experiment was performed in triplicate.

\subsubsection{Cell viability assay}

Cell viability was assessed by the crystal violet staining assay. HeLa cells ( 4000 cells/well) were seeded on a 96 -well plate in $200 \mu \mathrm{L}$ of folate-free RPMI-1640 medium, and allowed to adhere for $24 \mathrm{~h}$ at $37^{\circ} \mathrm{C}$. Then, the culture medium was replaced with either PLGA $/ \gamma$-PGA-FA nanoparticles, free DOX, or DOX-PLGA $/ \gamma$-PGA-FA nanoparticles at equivalent $10 \mu \mathrm{g} / \mathrm{mL}$ DOX concentration. Cells were incubated for $24 \mathrm{~h}, 48 \mathrm{~h}$ and $72 \mathrm{~h}$, at $37{ }^{\circ} \mathrm{C}$ under $5 \% \mathrm{CO}_{2}$ atmosphere, in sextuplicate. After a given time, the crystal violet assay was performed and untreated cells were considered as $100 \%$ of cell viability.

\subsection{Statistical analysis}

All data was analysed using OriginPro 8.6 software. Statistical analysis was performed with either one-way or two-way ANOVA and Bonferroni mean comparison at 0.05 significance level.

\section{Results}

\subsection{Preparation of PLGA nanoparticles}

The oil in water $(\mathrm{O} / \mathrm{W})$ emulsification-solvent evaporation method has been described as a relatively simple process to obtain PLGA-nanoparticles, where surfactant and polymer concentrations were important factors in the final characteristics of the nanoparticles. Based on the evaluated combinations, it was observed that the higher PVA concentration, the higher nanoparticle size. Thus, the lowest PVA concentration $(0.25 \% \mathrm{w} / \mathrm{v})$ was chosen as the optimal surfactant concentration. Once PVA concentration was established, two PLGA concentrations were analysed in order to achieve the highest DOX loading and encapsulation efficiencies. A concentration-dependant behaviour was observed, since $15 \mathrm{mg} / \mathrm{mL}$ PLGA concentration had higher efficiencies compared to $10 \mathrm{mg} / \mathrm{mL}$, remaining the lowest nanoparticle size. Finally, the smallest nanoparticle size was found at PLGA and PVA concentrations of $15 \mathrm{mg} / \mathrm{mL}$ and $0.25 \%(w / v)$, respectively. Volume mean diameter of PLGA nanoparticles before functionalization was found to be of 185.6 $\pm 47.2 \mathrm{~nm}$, showing a wide distribution (polydispersity index, PDI = 0.16 ) with an apparent monomodal population. Changes in size were observed by DLS when PLGA nanoparticles were conjugated to $\gamma$-PGA and FA (Table 1).

\subsection{Encapsulation efficiency (\%EE) and loading efficiency (\%LE)}

PLGA nanoparticles showed a loading efficiency behaviour dependant on polymer and surfactant concentrations. The highest loading efficiency $(0.33 \% \pm 0.01 \%)$ was taken as a mandatory parameter of system saturation, with an encapsulation efficiency of $47.9 \% \pm 1.8 \%$, when 104 $\mu \mathrm{g} / \mathrm{mL}$ of DOX concentration was tested.

Table 1

Characteristics of different nanoparticle systems (Mean \pm SD, $n=3$ ).

\begin{tabular}{llll}
\hline Nanoparticle system & Size $(\mathrm{nm})$ & PDI & Zeta potential $(\mathrm{mV})$ \\
\hline PLGA-NP & $185.6 \pm 47.2$ & $0.16 \pm 0.05$ & $-10.3 \pm 1.37$ \\
PLGA $/ \gamma$-PGA & $501 \pm 67.3$ & $0.09 \pm 0.03$ & $-16.4 \pm 1.99$ \\
PLGA $/ \gamma$-PGA-FA & $537 \pm 57.1$ & $0.10 \pm 0.07$ & $8.1 \pm 0.82$ \\
DOX-PLGA $/ \boldsymbol{\gamma}$-PGA-FA & $597 \pm 45.0$ & $0.02 \pm 0.01$ & $14.2 \pm 2.69$ \\
\hline
\end{tabular}

\subsection{Characterization studies}

\subsubsection{FT-IR spectroscopy}

The FT-IR spectrum of PLGA nanoparticles (Fig. 2a) showed the peaks corresponding to copolymer characteristic groups: $2942 \mathrm{~cm}^{-1}$ and $2918 \mathrm{~cm}^{-1}$ ( $\mathrm{CH}$ bend), $1737 \mathrm{~cm}^{-1}$ ( $\mathrm{C}=0$ of ester), $1376 \mathrm{~cm}^{-1}$ ( $-\mathrm{CH}_{3}$ from lactide), and $1300-1000 \mathrm{~cm}^{-1}$ (ester). A triple-peak absorption pattern is also present corresponding to bonds between monomeric units of lactide-lactide (L-L) at $1453 \mathrm{~cm}^{-1}$, glycolide-glycolide $(\mathrm{G}-\mathrm{G})$ at $1425 \mathrm{~cm}^{-1}$, and lactide-glycolide (L-G) at $1376 \mathrm{~cm}^{-1}$, within the PLGA polymer chains. Also, characteristic PVA peaks were seen at 3414-3240 $\mathrm{cm}^{-1}$, belonging to the $-\mathrm{OH}$ group from the alcohol. The peak at $1737 \mathrm{~cm}^{-1}$ is due to the presence of non-hydrolysed PVA, ergo acetylated residues from polyvinylacetate that was not totally converted to PVA. The characteristic peaks from the -OH group could be used to identify an interaction between PVA and PLGA in the nanoparticle, since similar peaks are present in the PLGA-NP spectrum [10,27]. The surface modification of PLGA-NP by $\gamma$-PGA (Fig. 2b) can be observed due to two peaks seen at $1570 \mathrm{~cm}^{-1}$, corresponding to the asymmetric stretching vibration of $\mathrm{COO}-$ and the $\mathrm{N}-\mathrm{H}$ bending vibration for amide II, and $1607 \mathrm{~cm}^{-1}$ corresponding to the symmetric stretching vibration of amide I present in the $\gamma$-PGA polymer [28].

The PLGA/ $\gamma$-PGA-FA nanoparticle spectrum (Fig. 2c) showed a band centred at $3299 \mathrm{~cm}^{-1}$, corresponding to the OH group and increased by the $\mathrm{N}-\mathrm{H}$ stretching vibration of the ethylenediamine structure used to modify the folic acid molecule. Also, the pteridine and phenyl ring skeleton of FA can be observed in the range of $1750-1500 \mathrm{~cm}^{-1}$ with a broad band at $1600 \mathrm{~cm}^{-1}$ corresponding to the overlapping of signals from aromatic $\mathrm{C}=\mathrm{C}$ and $\mathrm{C}=\mathrm{N}$ stretching vibrations and amide bond of the homo polyamide $\gamma$-PGA. Finally, in the DOX-PLGA $/ \gamma$-PGA-FA nanoparticle spectrum (Fig. $2 \mathrm{~d}$ ), an increase in the intensity of the band at $1757 \mathrm{~cm}^{-1}$ was observed, attributed to the $\mathrm{C}=\mathrm{O}$ stretching vibration from quinone and ketone groups of the DOX structure as well as the pteridine and phenyl ring skeleton from FA. These results allowed to confirm the presence of DOX and FA in PLGA nanoparticles.

\subsubsection{UV-Vis spectroscopy}

The reaction steps of PLGA/ $\gamma$-PGA-FA nanoparticle formation and DOX entrapment were followed by UV-Vis spectroscopy. The PLGA spectrum showed a signal increase in the UV region $(200 \mathrm{~nm}-$ $400 \mathrm{~nm}$ ) without defined bands, whereas $\gamma$-PGA polymer displayed a well-defined band in the UV region centred at $204 \mathrm{~nm}$ (Supplemental Fig. 1). The conjugation of $\gamma$-PGA to PLGA nanoparticles showed an intense and broad band centred at $208 \mathrm{~nm}$.

The DOX spectrum exhibited three narrow and well-defined bands identified at $230 \mathrm{~nm}, 253 \mathrm{~nm}$ and $290 \mathrm{~nm}$, whereas a wide and composed band was observed from $380 \mathrm{~nm}$ to $570 \mathrm{~nm}$, centred between 480 and $490 \mathrm{~nm}$ (Supplemental Fig. 2). When DOX was encapsulated into PLGA nanoparticles, the bands at $230 \mathrm{~nm}, 253 \mathrm{~nm}, 290 \mathrm{~nm}$, and $480 \mathrm{~nm}$ were found in the UV-Vis spectrum of DOX-loaded PLGA nanoparticles, with significant increase on baseline intensity due to particulate nature of the samples. Once the surface modification with $\gamma$-PGA was performed, the characteristic band of DOX at 480 was observed, which demonstrated that DOX remained in the modified nanoparticles. The band at $208 \mathrm{~nm}$, corresponding to the surface modification of PLGA nanoparticles with $\gamma$-PGA, was also observed (Fig. 3).

Folic acid analysed by UV-Vis spectroscopy showed two characteristic absorbance bands at $280 \mathrm{~nm}$ and $348 \mathrm{~nm}$. The successful FA conjugation to PLGA $/ \gamma$-PGA nanoparticles was demonstrated by means of the bands obtained at the same wavelength when the final PLGA $/ \gamma$-PGAFA system was analysed (Supplemental Fig. 3). Spectra of DOX-PLGA/ $\gamma$-PGA-FA nanoparticles and PLGA/ $\gamma$-PGA-FA nanoparticles were indistinguishable. However, signals of folic acid could be clearly seen in both spectra (Fig. 3). 


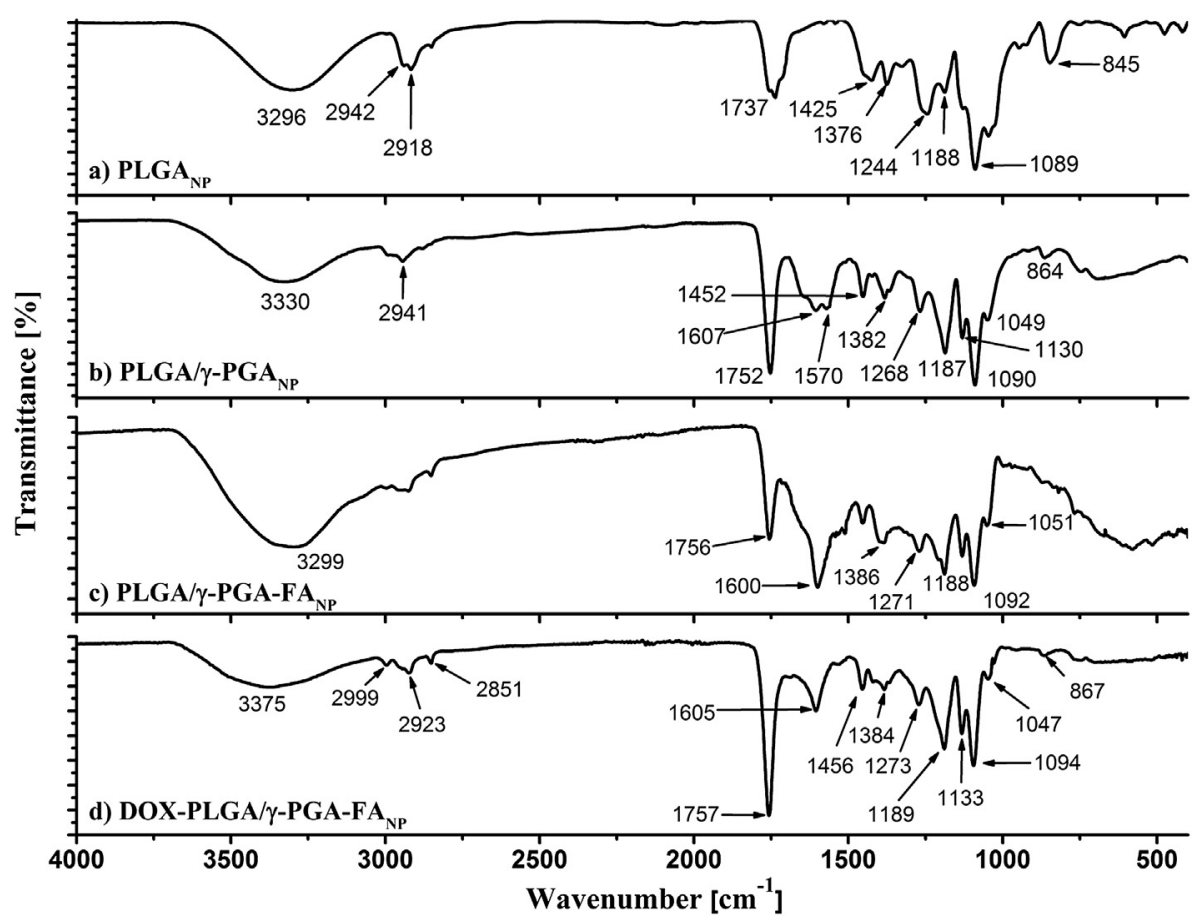

Fig. 2. FT-IR spectroscopy of a) PLGA NPs, b) PLGA NPs modified with $\gamma$-PGA, c) PLGA/ $\gamma$-PGA NPs functionalised with FA and d) DOX-loaded PLGA/ $\gamma$-PGA-FA NPs.

\subsubsection{SEM/TEM microscopy}

TEM/SEM images demonstrate the presence of polymeric structures of PLGA (Fig. 4a), with high density cores and distinctive quasi-spherical structures (Fig. 4c) with diameters ranging from 10 to $250 \mathrm{~nm}$. Nanoparticle formation was characterized by the maintenance of nanometric structures even when nanoparticles were DOX-loaded and FA-conjugated (Fig. $4 \mathrm{~b}$ ). The appearance of PLGA-NP, PLGA $/ \gamma$-PGA nanoparticles and PLGA $/ \gamma$-PGA-FA nanoparticles was indistinguishable by electron microscopy techniques.

\subsection{DOX-PLGA/ $\gamma-P G A-F A$ nanoparticle stability assay}

DOX-PLGA $/ \gamma$-PGA-FA nanoparticles showed no significant changes in particle size posterior freeze-drying, storage, and rehydration

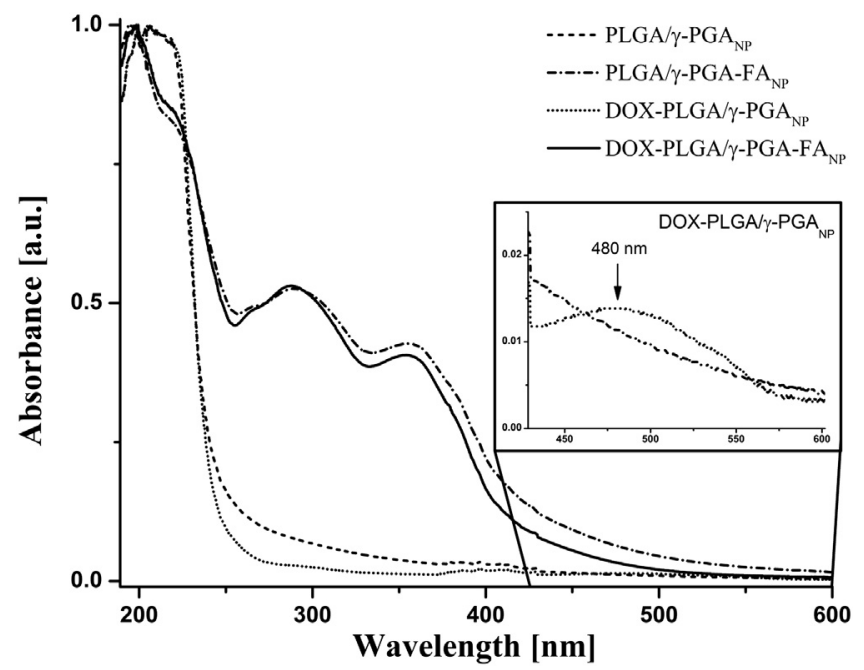

Fig. 3. DOX-PLGA/ $\gamma$-PGA-FA nanoparticles formation by UV-Vis spectroscopy. processes. No significant changes in nanoparticle size were also observed in rehydrated nanoparticles suspension after fifteen days (Supplemental Fig. 4).

\subsection{In vitro drug release kinetics}

In order to evaluate the potential of PLGA $/ \gamma$-PGA-FA nanoparticles as a drug carrier, in vitro release of DOX by DOX-PLGA/ $\gamma$-PGA-FA nanoparticles at two different $\mathrm{pH}$ values (7.4 and 5.3), and DOX-PLGA nanoparticles at pH 7.4 was evaluated. Fig. 5 displays release profiles of encapsulated systems. The release kinetics were fixed to a sigmoid model (Hill equation) to describe the relationship between non-linear drug release and exposure time in media at determined $\mathrm{pH}$. DOXPLGA nanoparticles showed the highest DOX release percentage throughout the experiment with a burst release in the course of the first day, with a value of $29.91 \pm 0.22 \%$. The Hill model predicted a maximum concentration release of $64 \pm 4 \%$ after the seventh day, with a mean release time at day 2, approximately. The burst phase was not observed in DOX-PLGA/ $\gamma$-PGA-FA nanoparticles at $\mathrm{pH} 5.3$ or $\mathrm{pH}$ 7.4. DOXPLGA $/ \gamma$-PGA-FA nanoparticles at $\mathrm{pH} 7.4$ showed DOX released of $12.05 \%$ $\pm 0.008 \%$ after 7 days, with a maximum drug release of $18.8 \pm 3.6 \%$ obtained by fixing it to the Hill equation. Meanwhile, DOX-PLGA $/ \gamma-P G A-$ FA nanoparticles at pH 5.3 showed a maximum drug release of $55.4 \pm$ $0.6 \%$ and a mean release time of seven days.

\subsection{In vitro cellular uptake study}

To demonstrate that folate can mediate the specific uptake of PLGA/ $\gamma$-PGA-FA nanoparticles via folate receptor, a blocked receptors model was chosen to conduct the study. Fig. 6 shows comparative PLGA $/ \gamma$ PGA-FA nanoparticle uptake by cells whose folate receptors were free or saturated with folic acid. The ANOVA test was conducted to evaluate the cellular uptake showing a statistical difference between blocked and non-blocked cells receptors. Non-blocked FA receptors on HeLa cells exhibited a 3.4-fold higher uptake than cell with blocked receptors. 

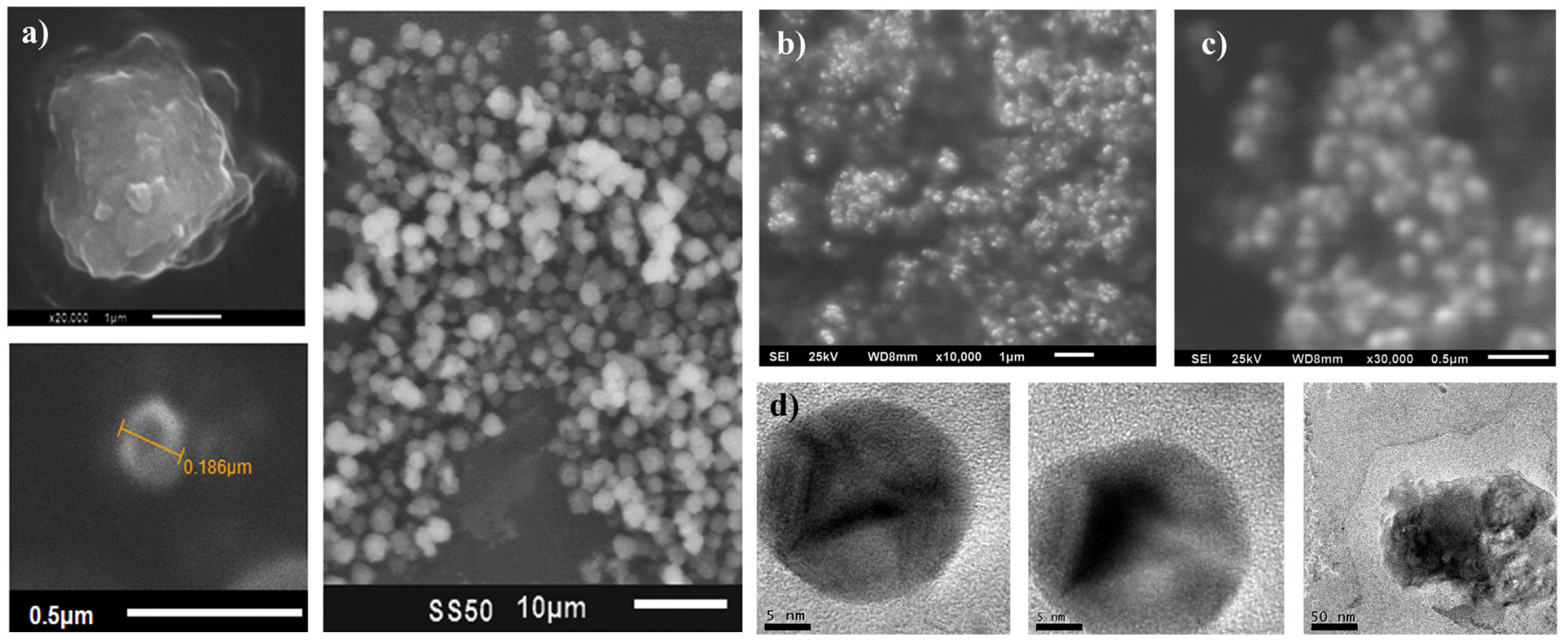

Fig. 4. SEM images of a) and b) PLGA NPs; c) DOX-PLGA/ $\gamma$-PGA-FA NPs and d) TEM of demonstrative shape found in DOX-PLGA/ $\gamma$-PGA-FA nanoparticles.

\subsection{Cell viability assay}

The effect of treatment with DOX-PLGA $/ \gamma$-PGA-FA nanoparticles, PLGA $\gamma$-PGA-FA nanoparticles and free DOX on HeLa cells, was evaluated. ANOVA and Bonferroni tests were used to compare treatments and exposure times $(p \leq 0.05)$. As revealed in Fig. 7 , the cell viability of free DOX with regards to DOX-PLGA $/ \gamma$-PGA-FA nanoparticles was lower at all exposure times. The effect on viability produced by DOX-PLGA $/ \gamma$ PGA-FA nanoparticles on HeLa cells was 1.8-fold higher at $72 \mathrm{~h}$ compared to $24 \mathrm{~h}$. Additionally, statistical differences among $24 \mathrm{~h}, 48 \mathrm{~h}$, and $72 \mathrm{~h}$ for PLGA/ $\gamma$-PGA-FA nanoparticles with respect to non-treated cells, were not found.

\section{Discussion}

Carbodiimide chemistry has been extensively used as a practical way to conjugate carboxylic acids to primary amines to obtain covalentlyconjugated systems with more advantages than those materials modified by adsorption processes. The $\gamma$-PGA was grafted to carboxylic acids present on PLGA-NP using a carbodiimide reaction and the sulfo-

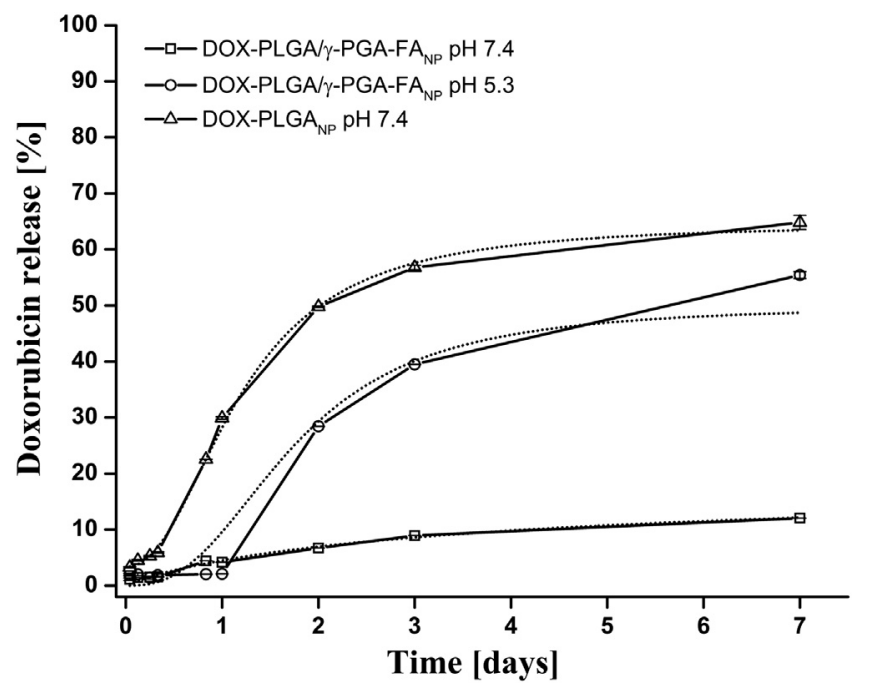

Fig. 5. In vitro release profiles of doxorubicin-loaded PLGA/ $\gamma$-PGA-FA nanoparticles at pH 5.3 and 7.4, and DOX-PLGA nanoparticles at pH 7.4. hydroxysuccinimide analogue in order to increase the yield reaction $[26,29]$. Prior to FA conjugation to PLGA $\gamma$-PGA nanoparticles, the FA was modified with EDA to obtain FA- $\mathrm{NH}_{2}$, so that there would be certainty that FA was successfully conjugated through the carboxylic acid. This modification does not affect the possibility of FA binding to folate receptors by specific recognition (pteridine group) [30].

PLGA nanoparticles showed a volume mean diameter of $185.6 \pm$ $47.2 \mathrm{~nm}$. There was a significant increase in size when $\gamma$-PGA was anchored to PLGA nanoparticles. These changes are due to the linkage of heavy $\gamma$-PGA polymer chains that were grafted to the nanoparticle surface. It has been observed that an increase in molecular weight of $\gamma$-PGA leads to an increase in particle size attributed to the extensibility of the hydrophilic $\gamma$-PGA chain, which enhances the swolling capability and promotes the space occupation of $\gamma$-PGA into nearby surroundings, randomly expanding on the surface of PLGA nanoparticles and leading to a high particle size and a broad distribution [19]. Additionally, the shrinkage of surface $\gamma$-PGA produces an adherent force among the polymeric colloids and can form interconnected clusters which could influence the particle size of PLGA/ $\gamma$-PGA nanoparticles measured by DLS $[19,31,32]$.

Folic acid conjugation to PLGA $\gamma$-PGA nanoparticles produced an increase in particle size measured by DLS ( $537 \mathrm{~nm} \pm 57.1 \mathrm{~nm})$. This increment was not as evident as that in the superficial modification of PLGA

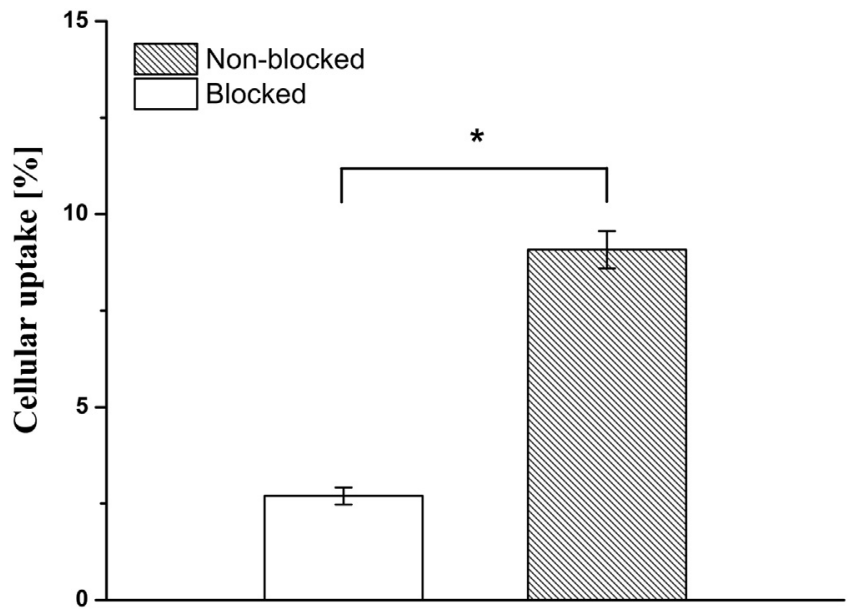

Fig. 6. Cellular uptake of PLGA/ $\gamma$-PGA-FA by blocked FA-receptor HeLa cells and nonblocked receptor HeLa cells. *Significantly difference at the 0.05 level. 


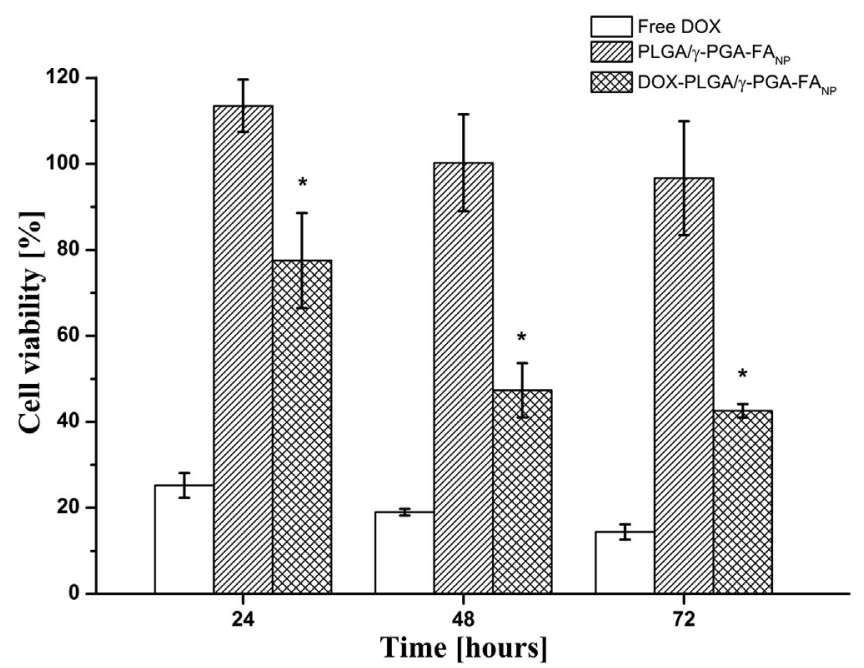

Fig. 7. Cell viability of HeLa cells after exposure to free DOX, DOX-loaded PLGA $/ \gamma$-PGA-FA NPs and PLGA $/ \gamma$-PGA-FA NPs at $24 \mathrm{~h}, 48 \mathrm{~h}$ and $72 \mathrm{~h}$. *Significantly difference at the 0.05 level.

nanoparticles with $\gamma$-PGA, although a high particle size remained. SEM and TEM images of the DOX-PLGA/ $\gamma$-PGA-FA final nanoparticle system displayed some regions with cumulus high density cores corresponding to nanoparticle structures, and the formation of clusters when the nanoparticles were modified with $\gamma$-PGA, was observed. These results correlate with the increase in diameter obtained by DLS. DOX-PLGA/ $\gamma$-PGAFA nanoparticles displayed particle sizes lower than $250 \mathrm{~nm}$ when they were found isolated by TEM or SEM techniques.

The physicochemical properties of nanoparticles, especially size and molecular weight, influence the biodistribution. After administration, small particles $(<20-30 \mathrm{~nm})$ are eliminated by renal excretion, whilst larger particles can be rapidly taken up by the mononuclear phagocytic system (MPS) cells. Although nanoparticles smaller than $150 \mathrm{~nm}$ can escape from the circulation through fenestrations of the endothelial barrier. However, in cancer development, tumour growth induces the development of neovasculature characterized by large fenestrations of 200-780 nm allowing higher nanoparticles passage [33-35]. In this sense we would expect a significant accumulation of engineered folic acid-nanoparticles on tumour tissue due to EPR effect, enhanced by interaction multimeric nanoparticles with folate cell receptors.

Freeze-dried formulation as well as the suspension form showed adequate stability for two months and fifteen days, respectively. Samples, posterior rehydration and size determination, showed no significant changes in particle size, suggesting that polymeric bulk structure prevents the degradation, nanoparticles fusion or coalescence during both freeze-drying procedure and the subsequently storage periods (rehydrated and non-rehydrated samples), and thus decreasing the need to add additional excipients.

Folic acid has been used in different types of nanoparticles such as metallic and polymeric nanoparticles. In this research, when FA was conjugated to PLGA/ $\gamma$-PGA nanoparticles, the zeta potential value changes from negative to positive, attributable to the modification on FA with ethylenediamine at the carboxyl group, which produced a loss of negative charges. Moreover, folic acid chemical structure contains a pteridine ring with amino groups present which could contribute to the change toward positive charge [36], so the subsequent binding of EDA-FA to PLGA $/ \gamma$-PGA nanoparticles leads to modification of zeta potential value. As soon as folic acid had been conjugated to the nanoparticles, a variation in the value of zeta potential occurs. In all cases, zeta potential of nanoparticles had negative values, but once folic acid is conjugated, the value of negative zeta potential shifts toward zero [37-40].

Surface modification, as well as functionalization of nanoparticles, was possible to perform even when nanoparticles were drug-loaded, which indicates that DOX is not involved in the carbodiimide reaction. It was observed that when nanoparticles were loaded with DOX, zeta potential value of the final systems PLGA $/ \gamma$-PGA-FA and DOX-PLGA $/ \gamma$ PGA-FA was incremented from $8.08 \mathrm{mV}$ to $14.2 \mathrm{mV}$, respectively, suggesting that a significant fraction of DOX remained at the nanoparticle surface in a protonated form, influencing the steric hindrance and minimizing the events of coalescence that occur among nanoparticles in a colloidal dispersion. Additionally, superficial DOX was evidenced throughout carbodiimide reactions, where a loss of approximately $43 \%$ of DOX was observed, due to the long stirring time required for reaction achievement and thus DOX entrapped superficially in the layer of PVA stabilizer could be released easily.

The UV-Vis and FT-IR measurement throughout the drug-loading, surface modification with $\gamma$-PGA, and FA conjugation procedures also demonstrated that DOX was loaded efficiently and nanoparticle modifications were made successfully. On the UV-Vis spectrum, the broad band found at $208 \mathrm{~nm}$, corresponding to the insertion of $\gamma$-PGA polymer to PLGA nanoparticles, represents a redshift after $\gamma$-PGA attachment, confirming the chromophore conjugation and effective surface modification of nanoparticles. FT-IR analysis showed significant differences in wavenumber within the range of $1760-1400 \mathrm{~cm}^{-1}$, when PLGA nanoparticles surface was modified. The FT-IR spectrum of PLGA/ $\gamma$ PGA nanoparticles showed two significant peaks at $1570 \mathrm{~cm}^{-1}$ and $1607 \mathrm{~cm}^{-1}$, due to the carboxylate groups and amide bounds, respectively, present in the polymeric chain of $\gamma$-PGA, which were not observed in PLGA-NP before modification. The $\gamma$-PGA polymer spectrum showed signals corresponding to the mentioned groups. However, these signals are shifted to larger wavenumbers in PLGA $/ \gamma$-PGA nanoparticles, due to covalent bindings (amide formation) as well as intermolecular van der Waals or hydrogen bond interactions between PLGA nanoparticles and the $\gamma$-PGA polymer, related to the three-dimensional arrangement of nanoparticle surface. Similar shifts toward higher energy frequencies were seen by Guan et al. [17] when gold nanoparticles were successfully capped with $\gamma$-PGA, modifying the surface.

FT-IR and UV-Vis analysis confirmed the conjugation of folic acid to PLGA $/ \gamma$-PGA nanoparticles. The UV-Vis spectrum showed the distinctive band of folic acid assigned to the $\pi-\pi^{*}$ transition of the pteridine ring around $280 \mathrm{~nm}$, which has been extensively described [41-43]. In the same way, the FT-IR spectrum of PLGA/ $\gamma$-PGA-FA nanoparticles showed the characteristic peaks corresponding to the structural units of the folic acid molecule. Also, the increased intensity of the broad band at $3299 \mathrm{~cm}^{-1}$ evidences the presence of hydrogen bonds, attributable to an increase in local concentration of amino groups from EDA bonded to FA.

The presence of DOX in DOX-PLGA/ $\gamma$-PGA-FA nanoparticles could also be demonstrated by FT-IR spectroscopy. The increase in the intensity of the band at $1757 \mathrm{~cm}^{-1}$, corresponding to quinone and ketone carbonyl groups indicated that the DOX rings are present in the final nanoparticulate system.

DOX has been previously encapsulated by PLGA nanosystems for cancer therapy, showing different encapsulation and loading efficiency percentages over $67 \%$ and $0.65 \%$, respectively, depending on the method and materials used for synthesis [44-48]. DOX-PLGA nanoparticles prepared by the single emulsification-solvent evaporation method and the use of PVA as stabilizer showed suitable encapsulation and loading efficiency percentages of $47.97 \pm 1.8 \%$ and $0.33 \pm 0.012 \%$, respectively. The DOX-PLGA nanoparticle formulation was performed to achieve the highest loading efficiency and, at the same time, a suitable DOX encapsulation along with an appropriate nanoparticle size. The increase in surfactant and polymer concentrations could allow higher DOX entrapment in function of the PVA layer increase and/or the amount of PLGA polymer available to entrap the drug. However, these changes may give rise to larger nanoparticles. Consequently, these factors should be considered in future experiments in order to optimize and improve the found results under the tested conditions in this study, by analysing different PVA and PLGA concentrations. 
Release behaviour of DOX-loaded PLGA nanoparticles exhibited an initial fast release, followed by a sustained phase, which is a similar drug release to that previously reported [49-53] at neutral $\mathrm{pH}$. The first stage is attributed to the amount of DOX entrapped on the PVA layer, followed by a controlled release as a consequence of PLGA degradation where the cleavage of ester bonds in the polymer chain produces lactic and glycolic acids, which induced autocatalysis of PLGA due to $\mathrm{pH}$ changes [54], leading to the disintegration of the nanoparticle structure and promoting the release of DOX. DOX release from DOX-PLGA $/ \gamma$-PGAFA responded to acidic conditions ( $\mathrm{pH}$ 5.3), with a significant increase in free DOX compared to physiological conditions, attributable to the PLGA and $\gamma$-PGA, which are $\mathrm{pH}$-sensitivity polymers $[55,56]$.

DOX-PLGA $/ \gamma$-PGA-FA nanoparticles at $\mathrm{pH} 7.4$ exhibited a lower release rate than that of DOX-PLGA nanoparticles. It has been seen that the hydrophilic characteristics of $\gamma$-PGA on the nanoparticle surface could allow the penetration of water to the hydrophobic DOX-PLGA nucleus, promoting the erosion and accelerating the release rate. However, a high molecular weight of $\gamma$-PGA leads to both a low quantity of the grafted $\gamma$-PGA on the particle surface, decreasing the erosion effect produced by water penetration as well as an increase in the level of chain entanglement and steric hindrance for releasing DOX. Additionally, the presence of moieties such as FA on nanoparticle surfaces could reduce the release rate of DOX. This is because FA could intensify the chain entanglements, elongate the diffusion path of DOX, diminish the concentration gradient, and hinder the release [19,57]. This study was carried out in saturation conditions and results indicate that the control on $\gamma$-PGA and FA conjugations opens the possibility for controlling the kinetic release by variating the proportion and molecular weight of polymer on the nanoparticle surface as well as the concentration of FA.

HeLa cells have been demonstrated that they over-express folate receptors $[58,59]$. To confirm the receptor specificity of cellular uptake, HeLa cells were incubated with free folic acid to block or reduce folate receptors on the surface of cancer cells prior to treatment with PLGA/ $\gamma$-PGA-FA nanoparticles [24]. FA-treated cells served as a model of cells with a low number of folate receptors. HeLa cells overexpressing folate receptors exposed to nanoparticles containing FA as a targeting ligand showed a notably higher uptake than those cells pre-treated with free FA. PLGA $/ \gamma$-PGA-FA nanoparticles also exhibited a non-specific uptake by non-FA-treated HeLa cells. However, results suggest that folic acid present on the PLGA/ $\gamma$-PGA-FA nanoparticle surface significantly improves the uptake by HeLa cells, supporting a receptor-mediated uptake mechanism.

The cell viability study was performed on HeLa cells in order to evaluate PLGA $/ \gamma$-PGA-FA nanoparticles as a potential drug carrier for cancer therapy. DOX concentration was homogenised for all treatments. Free DOX showed the highest cell death percentage at all exposure times with statistically significant difference $(p \leq 0.05)$. However, the effect of DOX-PLGA/ $\gamma$-PGA-FA was more evident after $72 \mathrm{~h}$ of treatment. This could be explained in terms of the DOX available to act against cancer cells. First, culture medium must possess an acidic $\mathrm{pH}$, mimicking the acidic microenvironment around tumours $[16,60]$, where DOXPLGA $/ \gamma$-PGA nanoparticles could start releasing DOX. Additionally, drug-loaded nanoparticles should also be internalised into cells, where the acidic conditions of lysosomes could finally degrade the polymeric system and thus achieve the amount of drug necessary to reach the desirable effect. This pH-dependant behaviour was observed in the profile release of DOX-PLGA $/ \gamma$-PGA-FA nanoparticles when these were evaluated at $\mathrm{pH}$ 5.3.

PLGA $/ \gamma$-PGA-FA nanoparticles did not demonstrate an effect on HeLa cells. The effect displayed by DOX-PLGA $/ \gamma$-PGA-FA was significantly higher compared to PLGA/ $\gamma$-PGA-FA nanoparticles without DOX, suggesting that the effect observed was due to the presence of the drug in nanoparticles.

In order to assess their therapeutic potential, DOX-PLGA $/ \gamma$-PGA-FA nanoparticles need to be tested on in vivo models to elucidate the physiological kinetics of nanoparticles at normal and abnormal conditions for design protocols for future experiments. PLGA $\gamma$-PGA conjugated to folic acid may provide an alternative therapy for chronic degenerative diseases such as cancer, where the overexpression of folate receptors offers a therapeutic target.

\section{Conclusion}

In this study, PLGA nanoparticles were properly prepared. The spectroscopy techniques demonstrate the correct surface modification and the successful conjugation with folic acid, resulting in an active drug targeting device. The cytotoxic effect against HeLa cells showed a dependence on drug release over the exposure time, due to the $\mathrm{pH}$-sensitive characteristics of DOX-PLGA/ $\gamma$-PGA-FA nanoparticles. The enhancement of cellular uptake by a receptor-mediated uptake mechanism of nanoparticles into HeLa cells was demonstrated. Therefore, the PLGA/ $\gamma$-PGA-FA system is a potential target-specific drug delivery system with molecular recognition of over-expressed folate receptors.

Supplementary data to this article can be found online at http://dx. doi.org/10.1016/j.msec.2017.03.145.

\section{Acknowledgments}

Funding: This study was supported by the International Atomic Energy Agency (CRP-F22064, Contract No. 18358) and the Universidad Autónoma del Estado de México, through the project No. 3543/ 2013CHT.

\section{References}

[1] K.B. Rathod, M.B. Patel, P.K. Parmar, S.R. Kharadi, P.V. Patel, K.S. Patel, Glimpses of current advances of nanotechnology in therapeutics, Int J Pharm Pharm Sci 3 (2011) 8-12

[2] R. Duncan, Polymer therapeutics as nanomedicines: new perspectives, Curr. Opin. Biotechnol. 22 (2011) 492-501, http://dx.doi.org/10.1016/j.copbio.2011.05.507.

[3] H. Karimi-Maleh, A.F. Shojaei, K. Tabatabaeian, F. Karimi, S. Shakeri, R. Moradi, Simultaneous determination of 6-mercaptopruine, 6-thioguanine and dasatinib as three important anticancer drugs using nanostructure voltammetric sensor employing Pt/MWCNTs and 1-butyl-3-methylimidazolium hexafluoro phosphate, Biosens. Bioelectron. 86 (2016) 879-884, http://dx.doi.org/10.1016/j.bios.2016.07. 086.

[4] H. Karimi-Maleh, F. Tahernejad-Javazmi, A.A. Ensafi, R. Moradi, S. Mallakpour, H. Beitollahi, A high sensitive biosensor based on FePt/CNTs nanocomposite/N-(4hydroxyphenyl)-3,5-dinitrobenzamide modified carbon paste electrode for simultaneous determination of glutathione and piroxicam, Biosens. Bioelectron. 60 (2014) 1-7, http://dx.doi.org/10.1016/j.bios.2014.03.055.

[5] P.R. Lockman, R.J. Mumper, M.A. Khan, D.D. Allen, Nanoparticle technology for drug delivery across the blood-brain barrier, Drug Dev. Ind. Pharm. 28 (2002) 1-13, http://dx.doi.org/10.1081/DDC-120001481.

[6] D. Feldman, Polymer nanocomposites in medicine, J. Macromol. Sci. A. 53 (2016) 55-62, http://dx.doi.org/10.1080/10601325.2016.1110459.

[7] D. Moreno, C.T. de Ilarduya, E. Bandrés, M. Buñuales, M. Azcona, J. García-Foncillas, M.J. Garrido, Characterization of cisplatin cytotoxicity delivered from PLGA-systems, Eur. J. Pharm. Biopharm. 68 (2008) 503-512, http://dx.doi.org/10.1016/j.ejpb.2007. 08.006.

[8] R. Gowda, N.R. Jones, S. Banerjee, G.P. Robertson, Use of Nanotechnology to Develop Multi-Drug Inhibitors For Cancer Therapy, J. Nanosci. Nanotechnol. 4 (2013), http:// dx.doi.org/10.4172/2157-7439.1000184.

[9] R.L. McCall, R.W. Sirianni, PLGA nanoparticles formed by single- or double-emulsion with vitamin E-TPGS, J. Vis. Exp. (2013) (51015) 10.3791/51015.

[10] M.M. Stevanović, B. Jordović, D.P. Uskoković, Preparation and characterization of poly(D,L-lactide-co-glycolide) nanoparticles containing ascorbic acid, J. Biomed. Biotechnol. 2007 (2007), http://dx.doi.org/10.1155/2007/84965.

[11] P. Botella, M. Quesada, V. Vicente, K. Fabregat, In vitro delivery of docetaxel to cancer cells by hybrid PLGA @ organosilica nanoparticles with redox-sensitive molecular gates, in: NSTI (Ed.), Nanotechnol. 2014 MEMS, Fluid. Bio Syst. Medical, Comput. Photonics, Taylor \& Francis 2014, pp. 355-358.

[12] S. Rahimian, M.F. Fransen, J. Willem Kleinovink, M. Amidi, F. Ossendorp, W.E. Hennink, Particulate systems based on poly(lactic-co-glycolic)acid (pLGA) for immunotherapy of cancer, Curr. Pharm. Des. 21 (2015) 4201-4216.

[13] I. Kim, H.J. Byeon, T.H. Kim, E.S. Lee, K.T. Oh, B.S. Shin, K.C. Lee, Y.S. Youn, Doxorubicin-loaded porous PLGA microparticles with surface attached TRAIL for the inhalation treatment of metastatic lung cancer, Biomaterials 34 (2013) 6444-6453, http://dx.doi.org/10.1016/j.biomaterials.2013.05.018.

[14] D. Le Broc-Ryckewaert, R. Carpentier, E. Lipka, S. Daher, C. Vaccher, D. Betbeder, C. Furman, Development of innovative paclitaxel-loaded small PLGA nanoparticles: Study of their antiproliferative activity and their molecular interactions on prostatic 
cancer cells, Int. J. Pharm. 454 (2013) 712-719, http://dx.doi.org/10.1016/j.ijpharm. 2013.05.018

[15] P. Verderio, P. Bonetti, M. Colombo, L. Pandolfi, D. Prosperi, Intracellular drug release from curcumin-loaded PLGA nanoparticles induces G2/M block in breast cance cells, Biomacromolecules 14 (2013) 672-682, http://dx.doi.org/10.1021/ bm3017324.

[16] J.M. Shen, F.Y. Gao, T. Yin, H.X. Zhang, M. Ma, Y.J. Yang, F. Yue, CRGD-functionalized polymeric magnetic nanoparticles as a dual-drug delivery system for safe targeted cancer therapy, Pharmacol. Res. 70 (2013) 102-115, http://dx.doi.org/10.1016/j. phrs.2013.01.009.

[17] H. Guan, W. Wang, X. Liu, J. Liang, Real-time visualization of colorimetric probe for $\mathrm{pH}$-sensitive based on poly-( $\gamma$-glutamic acid)-functionalized gold nanoparticles, Colloids Surf. A Physicochem. Eng. Asp. 448 (2014) 147-153, http://dx.doi.org/10. 1016/j.colsurfa.2014.02.026

[18] F. Hellmers, P. Ferguson, J. Koropatnick, R. Krull, A. Margaritis, Characterization and in vitro cytotoxicity of doxorubicin-loaded $\gamma$-polyglutamic acid-chitosan composite nanoparticles, Biochem. Eng. J. 75 (2013) 72-78, http://dx.doi.org/10.1016/j.bej. 2013.03.019.

[19] Y.C. Kuo, H.W. Yu, Transport of saquinavir across human brain-microvascular endothelial cells by poly(lactide-co-glycolide) nanoparticles with surface poly-(??glutamic acid), Int. J. Pharm. 416 (2011) 365-375, http://dx.doi.org/10.1016/j. ijpharm.2011.06.037.

[20] F. Shima, T. Akagi, T. Uto, M. Akashi, Manipulating the antigen-specific immune response by the hydrophobicity of amphiphilic poly( $\gamma$-glutamic acid) nanoparticles, Biomaterials 34 (2013) 9709-9716, http://dx.doi.org/10.1016/j.biomaterials.2013. 08.064.

[21] R. Toita, K. Nakao, A. Mahara, T. Yamaoka, M. Akashi, Biodistribution of vaccines comprised of hydrophobically-modified poly $(\gamma$-glutamic acid) nanoparticles and antigen proteins using fluorescence imaging, Bioorg. Med. Chem. 21 (2013) 6608-6615, http://dx.doi.org/10.1016/j.bmc.2013.08.024.

[22] N. Tomiya, J.G. Jardim, J. Hou, R. Pastrana-Mena, R.R. Dinglasan, Y.C. Lee, Livertargeting of primaquine-(poly- $\gamma$-glutamic acid) and its degradation in rat hepatocytes, Bioorg. Med. Chem. 21 (2013) 5275-5281, http://dx.doi.org/10.1016/j.bmc 2013.06.028.

[23] Y. Yang, J. Cai, X. Zhuang, Z. Guo, X. Jing, X. Chen, PH-dependent self-assembly of amphiphilic poly(l-glutamic acid)-block-poly(lactic-co-glycolic acid) copolymers, Polymer 51 (2010) 2676-2682 (Guildf) 10.1016/j.polymer.2010.04.008.

[24] I. Hajdu, G. Trencesényi, M. Bodnár, M. Emri, G. Bánfalvi, J. Sikula, T. Márián, J. Kollár G. Vámosi, J. Borbély, Tumor-specific localization of self-assembled nanoparticle PET/MR modalities, Anticancer Res. 34 (2014) 49-59.

[25] L. Jaimes-Aguirre, B.V. Gibbens-Bandala, E. Morales-Avila, B.E. Ocampo-García, M. Seyedeh-Fatemeh, A. Amirhosein, Polymer-based drug delivery systems, development and pre-clinical status, Curr. Pharm. Des. 22 (2016).

[26] M.K. Yu, J. Park, S. Jon, Targeting strategies for multifunctional nanoparticles in cancer imaging and therapy, Theranostics 2 (2012) 3-44, http://dx.doi.org/10.7150/ thno.3463.

[27] M.R. Kreitz, J.A. Domm, E. Mathiowitz, Controlled delivery of therapeutics from microporous membranes. II. In vitro degradation and release of heparin-loaded poly(D,L-lactide-coglycolide), Biomaterials 18 (1997) 1645-1651, http://dx.doi. org/10.1016/S0142-9612(97)00106-3.

[28] S. Karmaker, T.K. Saha, Y. Yoshikawa, H. Yasui, H. Sakurai, A novel drug delivery system for type 1 diabetes: insulin-mimetic vanadyl-poly (gamma-glutamic acid) complex, J. Inorg. Biochem. 100 (2006) 1535-1546, http://dx.doi.org/10.1016/j. jinorgbio.2006.05.005.

[29] G.T. Hermanson, Bioconjugate techniques, Academic press, 2013.

[30] L. Aranda-Lara, G. Ferro-Flores, F. de M. Ramírez, B. Ocampo-García, C. SantosCuevas, L. Díaz-Nieto, K. Isaac-Olivé, Improved radiopharmaceutical based on 99mTc-Bombesin-folate for breast tumour imaging, Nucl. Med. Commun. 37 (2016) 377-386, http://dx.doi.org/10.1097/MNM.0000000000000460.

31] H. Guan, X. Liu, W. Wang, J. Liang, Direct colorimetric biosensing of mercury(II) ion based on aggregation of poly-(??-glutamic acid)-functionalized gold nanoparticles, Spectrochim. Acta A Mol. Biomol. Spectrosc. 121 (2014) 527-532, http://dx.doi. org/10.1016/j.saa.2013.10.107.

32] R. Zhang, S. Xu, J. Luo, D. Shi, C. Liu, X. Liu, One-pot green synthesis of nanohybrid structures: gold nanoparticles in poly $(\boldsymbol{\gamma}$-glutamic acid) copolymer nanoparticles, RSC Adv. 4 (2014) 25106-25113, http://dx.doi.org/10.1039/c4ra01094a.

[33] M. Gaumet, A. Vargas, R. Gurny, F. Delie, Nanoparticles for drug delivery: the need for precision in reporting particle size parameters, Eur. J. Pharm. Biopharm. 69 (2008) 1-9, http://dx.doi.org/10.1016/j.ejpb.2007.08.001.

[34] R. Xu, Progress in nanoparticles characterization: sizing and zeta potential measurement, Particuology 6 (2008) 112-115, http://dx.doi.org/10.1016/j.partic.2007.12. 002.

[35] K.W. Powers, S.C. Brown, V.B. Krishna, S.C. Wasdo, B.M. Moudgil, S.M. Roberts, Research strategies for safety evaluation of nanomaterials. Part VI. characterization of nanoscale particles for toxicological evaluation, Toxicol. Sci. 90 (2006) 296-303, http://dx.doi.org/10.1093/toxsci/kfj099.

[36] G. Li, D. Magana, R.B. Dyer, Photoinduced electron transfer in folic acid investigated by ultrafast infrared spectroscopy, J. Phys. Chem. B 116 (2012) 3467-3475, http:// dx.doi.org/10.1021/jp300392a.Photoinduced.

[37] H. Song, C. Su, W. Cui, B. Zhu, L. Liu, Z. Chen, L. Zhao, Folic acid-chitosan conjugated nanoparticles for improving tumor-targeted drug delivery, Biomed. Res. Int. 2013 (2013) 1-6, http://dx.doi.org/10.1155/2013/723158.

[38] M. Das, D. Bandyopadhyay, D. Mishra, S. Datir, P. Dhak, S. Jain, T.K. Maiti, A. Basak, P. Pramanik, "Clickable", trifunctional magnetite nanoparticles and their chemoselective Biofunctionalization, Bioconjug. Chem. 22 (2011) 1181-1193, http://dx.doi.org/10.1021/bc2000484.
[39] Z. Zhang. J. Jia, Y. Lai, Y. Ma, J. Weng. L. Sun, Conjugating folic acid to gold nanoparticles through glutathione for targeting and detecting cancer cells, Bioorg. Med. Chem. 18 (2010) 5528-5534, http://dx.doi.org/10.1016/j.bmc.2010.06.045.

[40] M. Das, D. Mishra, T.K. Maiti, A. Basak, P. Pramanik, Bio-functionalization of magnetite nanoparticles using an aminophosphonic acid coupling agent: new, ultradispersed, iron-oxide folate nanoconjugates for cancer-specific targeting, Nanotechnology 19 (2008) (415101).

[41] Z. Li, S. Liu, S. Wang. L. Oiang, T. Yang. H. Wang, H. Mohwald, X. Cui, Synthesis of folic acid functionalized redox-responsive magnetic proteinous microcapsules for targeted drug delivery, J. Colloid Interface Sci. 450 (2015) 325-331, http://dx.doi. org/10.1016/j.jcis.2015.03.036.

[42] I.B. Bwatanglang. F. Mohammad, N.A. Yusof, J. Abdullah, M.Z. Hussein, N.B. Alitheen, $\mathrm{N}$. Abu, Folic acid targeted Mn:ZnS quantum dots for theranostic applications of cancer cell imaging and therapy, Int. J. Nanomedicine 11 (2016) 413-428, http://dx.doi. org/10.2147/ijn.s90198.

[43] K. Patel, B. Sundara Raj, Y. Chen, X. Lou, Cytotoxicity of folic acid conjugated hollow silica nanoparticles toward Caco2 and 3T3 cells, with and without encapsulated DOX, Colloids Surf. B Biointerfaces. 140 (2016) 213-222, http://dx.doi.org/10. 1016/j.colsurfb.2015.12.046.

[44] F. Tewes, E. Munnier, B. Antoon, L. Ngaboni Okassa, S. Cohen-Jonathan, H. Marchais, L. Douziech-Eyrolles, M. Souc, P. Dubois, I. Chourpa, Comparative study of doxorubicin-loaded poly(lactide-co-glycolide) nanoparticles prepared by single and double emulsion methods, Eur. J. Pharm. Biopharm. 66 (2007) 488-492, http://dx.doi.org/ 10.1016/j.ejpb.2007.02.016.

[45] T. Lei, S. Srinivasan, Y. Tang, R. Manchanda, A. Fernandez-Fernandez, A.J. Mcgoron, Targeted Delivery of Doxorubicin by PLGA Nanoparticles Increases Drug Uptake in Cancer Cell Lines, in: K.E. Herold, J. Vossoughi, W.E. Bentley (Eds.), 26th South. Biomed. Eng. Conf. SBEC 2010, April 30-May 2, 2010, Coll. Park. Maryland, USA, Springer Berlin Heidelberg, Berlin, Heidelberg 2010, pp. 224-227, http://dx.doi. org/10.1007/978-3-642-14998-6_57.

[46] R. Kumar, A. Kulkarni, J. Nabulsi, D.K. Nagesha, R. Cormack, M.G. Makrigiorgos, S. Sridhar, Facile synthesis of PEGylated PLGA nanoparticles encapsulating doxorubicin and its in vitro evaluation as potent drug delivery vehicle, Drug Deliv. Transl. Res. 3 (2013) 299-308, http://dx.doi.org/10.1007/s13346-012-0124-9.

[47] J.-L. Li, C.-L. Zheng, J.-P. Liu, J.-B. Zhu, Formulation and process optimization of doxorubicin-loaded PLGA nanoparticles and its in vitro release, Yao Xue Xue Bao 48 (2013) 759-766.

[48] L. Deng, L. Li, H. Yang, L. Li, F. Zhao, C. Wu, Y. Liu, Development and optimization of doxorubicin loaded poly(lactic-co-glycolic acid) nanobubbles for drug delivery into HeLa cells, J. Nanosci. Nanotechnol. 14 (2014) 2947-2954, http://dx.doi.org/10. 1166/jnn.2014.8633.

[49] N. Alam, V. Khare, R. Dubey, A. Saneja, M. Kushwaha, G. Singh, N. Sharma, B. Chandan, P.N. Gupta, Biodegradable polymeric system for cisplatin delivery: development, in vitro characterization and investigation of toxicity profile, Mater. Sci. Eng. C 38 (2014) 85-93, http://dx.doi.org/10.1016/j.msec.2014.01.043.

[50] J. Guo, X. Gao, L. Su, H. Xia, G. Gu, Z. Pang, X. Jiang, L. Yao, J. Chen, H. Chen, Aptamerfunctionalized PEG-PLGA nanoparticles for enhanced anti-glioma drug delivery, Biomaterials 32 (2011) 8010-8020, http://dx.doi.org/10.1016/j.biomaterials.2011.07. 004.

[51] C. Clawson, C.T. Huang, D. Futalan, D. Martin Seible, R. Saenz, M. Larsson, W. Ma, B. Minev, F. Zhang, M. Ozkan, C. Ozkan, S. Esener, D. Messmer, Delivery of a peptide via poly(d,l-lactic-co-glycolic) acid nanoparticles enhances its dendritic cell-stimulatory capacity, Nanomed. Nanotechnol., Biol. Med. 6 (2010) 651-661, http://dx.doi. org/10.1016/.nano.2010.03.001.

[52] J.M. Chan, L. Zhang, K.P. Yuet, G. Liao, J.W. Rhee, R. Langer, O.C. Farokhzad, PLGA-lecithin-PEG core-shell nanoparticles for controlled drug delivery, Biomaterials 30 (2009) 1627-1634, http://dx.doi.org/10.1016/j.biomaterials.2008.12.013.

[53] D.H. Kim, D.C. Martin, Sustained release of dexamethasone from hydrophilic matrices using PLGA nanoparticles for neural drug delivery, Biomaterials 27 (2006) 3031-3037, http://dx.doi.org/10.1016/j.biomaterials.2005.12.021.

[54] M.L.T. Zweers, G.H.M. Engbers, D.W. Grijpma, J. Feijen, In vitro degradation of nanoparticles prepared from polymers based on DL-lactide, glycolide and poly(ethylene oxide), J. Control. Release 100 (2004) 347-356, http://dx.doi.org/10.1016/j.jconrel. 2004.09.008.

[55] A. Beloqui, R. Coco, P.B. Memvanga, B. Ucakar, A. Des Rieux, V. Préat, PH-sensitive nanoparticles for colonic delivery of curcumin in inflammatory bowel disease, Int. J. Pharm. 473 (2014) 203-212, http://dx.doi.org/10.1016/j.ijpharm.2014.07.009,

[56] W. Zeng, G. Chen, Y. Zhang, K. Wu, Z. Liang, Studies on the UV spectrum of poly(??glutamic acid) based on development of a simple quantitative method, Int. J. Biol. Macromol. 51 (2012) 83-90, http://dx.doi.org/10.1016/j.jibiomac.2012.04.005.

[57] Y.C. Kuo, H.W. Yu, Polyethyleneimine/poly-(gamma-glutamic acid)/poly(lactide-coglycolide) nanoparticles for loading and releasing antiretroviral drug, Colloids Surf. B Biointerfaces 88 (2011) 158-164, http://dx.doi.org/10.1016/j.colsurfb.2011.06. 026.

[58] S.J.T. Rezaei, L. Sarbaz, H. Niknejad, Folate-decorated redox/pH dual-responsive degradable prodrug micelles for tumor triggered targeted drug delivery, RSC Adv. 6 (2016) 62630-62639, http://dx.doi.org/10.1039/c0xx00000x.

[59] H. Yang, M. Xu, S. Li, X. Shen, T. Li, J. Yan, C. Zhang, C. Wu, H. Zeng, Y. Liu, Chitosan hybrid nanoparticles as a theranostic platform for targeted doxorubicin/VEGF shRNA co-delivery and dual-modality fluorescence imaging, RSC Adv. 6 (2016) 29685-29696, http://dx.doi.org/10.1039/C6RA03843C

[60] J.M. Shen, W.J. Tang, X.L. Zhang, T. Chen, H.X. Zhang, A novel carboxymethyl chitosan-based folate/Fe 30 4/CdTe nanoparticle for targeted drug delivery and cell imaging, Carbohydr. Polym. 88 (2012) 239-249, http://dx.doi.org/10.1016/j.carbpol. 2011.11.087. 